\title{
Simultaneous pharmacokinetics of indomethacin in serum and synovial fluid
}

\author{
H. W. EMORI, G. D. CHAMPION, R. BLUESTONE, AND H. E. PAUluS
}

From the Department of Medicine, Veterans Administration, Wadsworth Hospital, Los Angeles, California 90073; St. Vincent's Hospital, Sydney, Australia; and the Department of Medicine, UCLA School of Medicine, Los Angeles, California 90024, U.S.A.

Much evidence has been presented to support the concept that the proliferative and destructive changes of rheumatoid arthritis (RA) are related to synovial immune complex deposition with subsequent release of injurious leucocyte lysosomal enzymes into the synovial membrane and synovial fluid (Zvaifler, 1970). The evidence for a local pathogenic process within the rheumatoid joint, coupled with the pharmacological principle that the efficacy of most therapeutic agents is related to serum drug concentrations and especially to drug concentration at the target receptor cells (Rosenoer and Gill, 1972; Koch-Weser, 1972), suggests that the measurement of synovial fluid drug levels might help to establish optimal anti-inflammatory drug regimens for patients with RA.

Indomethacin (a 3-indolyl-acetic acid derivative) is a commonly used anti-inflammatory drug. Recent observations have been reported by Duggan, Hogans, Kwan, and McMahon (1972), on its metabolism; Hvidberg, Lausen, and Jansen (1972), on plasma concentrations and protein binding; and by Caruso (1971) on serum and synovial fluid concenAccepted for publication February 12, 1973.

Supported by Veterans Administration Training Grant TR 54 and USPHS Grant GM 15759.

Table Indomethacin concentrations $(\mu \mathrm{g} . / \mathrm{ml}$.$) in serum (S)$ and synovial fluid $(S F)$ of seven patients with rheumatoid arthritis

\begin{tabular}{|c|c|c|c|c|c|c|c|c|c|c|c|c|c|c|c|c|c|c|}
\hline \multirow{3}{*}{$\begin{array}{c}\text { Time } \\
\text { min.) }\end{array}$} & \multicolumn{18}{|c|}{ Patients* } \\
\hline & \multicolumn{2}{|l|}{1} & \multicolumn{2}{|l|}{2} & \multicolumn{2}{|l|}{$3 *$} & \multicolumn{2}{|l|}{4} & \multicolumn{2}{|l|}{5} & \multicolumn{2}{|l|}{6} & \multicolumn{2}{|l|}{7} & \multicolumn{2}{|l|}{$8^{*}$} & \multicolumn{2}{|c|}{ Mean $\pm S E M$} \\
\hline & $\overline{\mathbf{S}}$ & SF & s & SF & $\mathrm{s}$ & SF & S & SF & s & SF & $\mathbf{S}$ & SF & s & SF & $\mathbf{s}$ & SF & s & SF \\
\hline 30 & $4 \cdot 50$ & 0.15 & 2.00 & 0.15 & ND & ND & 1.52 & $0 \cdot 20$ & $3 \cdot 10$ & $0 \cdot 15$ & ND & ND & $2 \cdot 74$ & ND & $1 \cdot 50$ & $0 \cdot 10$ & $2.56 \pm 0.51$ & $0 \cdot 13 \pm 0 \cdot 10$ \\
\hline 60 & 3.45 & 0.32 & 2.75 & 0.22 & ND & ND & ND & ND & $2 \cdot 50$ & 0.60 & $2 \cdot 72$ & 0.37 & 3.00 & 0.40 & $2 \cdot 90$ & 0.78 & $2 \cdot 88 \pm 0.15$ & $0.37 \pm 0.06$ \\
\hline 90 & $2 \cdot 00$ & 0.50 & 1.60 & $0 \cdot 30$ & ND & ND & ND & ND & 2.00 & ND & 1.85 & ND & 1.47 & 0.40 & 3.05 & 0.78 & $2.00 \pm 0.25$ & $0.52 \pm 0.17$ \\
\hline 120 & 1.62 & 0.50 & 0.95 & 0.32 & $1 \cdot 37$ & $\begin{array}{l}0.92 \dagger \\
0.90\end{array}$ & $\overline{\text { ND }}$ & ND & 1.45 & 0.90 & 52 & 0.50 & JD & 0.60 & 70 & 0.90 & .26 & $0.69 \pm 0.09$ \\
\hline 210 & 0.54 & $\overline{0.52}$ & 0.45 & 0.35 & ND & ND & $\overline{\mathrm{ND}}$ & ND & $\overline{\text { ND }}$ & ND & 0.75 & 0.75 & 0.45 & 0.55 & 0.88 & 0.80 & $0.61 \pm 0.32$ & $0.59 \pm 0.09$ \\
\hline 300 & 0.42 & 0.52 & 0.40 & $0 \cdot 35$ & 0.45 & $\begin{array}{l}065 \dagger \\
0.65\end{array}$ & ND & ND & 0.45 & 0.65 & 0.55 & 0.56 & 0.40 & 0.48 & 0.39 & 0.75 & $0.44 \pm 0.03$ & 0.57 \\
\hline 420 & ND & ND & ND & ND & ND & ND & ND & ND & ND & ND & 0.40 & 0.53 & 0.30 & 0.40 & 0.35 & 0.50 & $0.35 \pm 0.02$ & $0.47 \pm 0.03$ \\
\hline & ND & ND & D & JD & ND & ID & JD & D & 28 & 35 & 35 & $\begin{array}{l}0.48 \dagger \\
0.55\end{array}$ & 0.35 & 40 & 37 & $\begin{array}{l}0.35 \dagger \\
0.28\end{array}$ & $0.34 \pm 0.02$ & $0.40 \pm 0.04$ \\
\hline
\end{tabular}

trations of the drug after intravenous infusion in patients with chronic polyarthritis. This report describes the simultaneous pharmacokinetics of indomethacin in the serum and synovial fluid of patients with RA after oral administration of the drug.

\section{Patients and methods}

Seven patients with classical or definite RA (Ropes, Bennett, Cobb, Jacox, and Jessar, 1959) and chronic knee joint effusions were studied; one patient was studied twice giving a total of eight trials (Table). Three patients were hospitalized, the remainder were studied as outpatients; all were allowed to ambulate freely during the study. All patients were free of overt renal or hepatic disease by usual clinical and laboratory indicators.

After an 8-hr fast the patients were given $50 \mathrm{mg}$. indomethacin by mouth with water. Samples of blood $(15 \mathrm{ml}$.) and synovial fluid $(8 \mathrm{ml}$.) were taken at $30,60,90,120,300$, 420, and 540-min. intervals after drug ingestion. Serum was obtained by centrifugation and all samples were stored at $-4^{\circ} \mathrm{C}$. until analysed within 3 weeks. Repeat analysis of both serum and synovial fluid indomethacin levels after 4 months' storage at $-4^{\circ} \mathrm{C}$. demonstrated no change in drug levels. 
Indomethacin assays on both serum and synovial fluid were performed using a modification of the method of Hucker, Zacchei, Cox, Brodie, and Cantwell (1966). This method was suggested to us by the manufacturer of the drug.* In this method $3 \mathrm{ml}$. of sample are buffered with $2 \mathrm{ml} .0 .5 \mathrm{M}, \mathrm{pH} 5$ citrate; the indomethacin is then extracted with $25 \mathrm{ml}$. of a solution containing fluorescencefree heptane ( 97 per cent.) and amyl alcohol ( 3 per cent.). The heptane phase is washed twice with an equal volume of citrate buffer. A 15-ml. aliquot of the washed heptane phase is alkalinized with $4 \mathrm{ml}$. of $0.2 \mathrm{M} \mathrm{Na}_{2} \mathrm{CO}_{3}$ to extract the drug. The aqueous phase after centrifugation is removed for fluorescence intensity measurement. Occasionally, turbidity in the aqueous phase at this point required further centrifugation. The clear aqueous phase was read in an Aminco SPF 125 spectrophotofluorometer at excitation wave length $295 \mathrm{~m} \mu$ and emission was measured at a wave length $375 \mathrm{~m} \mu$ in quartz cuvettes. A water blank and two serum standards of 2.5 and $5 \mu \mathrm{g}$. $/ \mathrm{ml}$. were analysed with each set of determinations. Repeated assays of standards, using fresh drug at weekly intervals, were accurate to $0.08 \mu \mathrm{g}$. (SEM $=0.003$ ). In earlier studies by our laboratory no interference in the spectrofluorometric absorbance reading of known indomethacin concentrations in serum was noted when a known concentration of sodium salicylate (30 mg./100 ml.) was added (Champion, Paulus, Morgan, Okun, Pearson, and Sarkissian, 1972).

\section{Results}

A mean peak serum level of $2 \cdot 88 \mu \mathrm{g} . / \mathrm{ml}$. (SEM $=0 \cdot 15$ ) occurred $1 \mathrm{hr}$ following the oral administration of a single 50-mg. dose (Fig. 1). For synovial fluid, the mean peak was lower, $0.69 \mu \mathrm{g} . / \mathrm{ml}$. (SEM $=0.24)$, and occurred $2 \mathrm{hrs}$ after the dose.

*Personal communication: J. E. Baer, Merck Institute for Therapeutic Research, West Point, Pa. 19486.

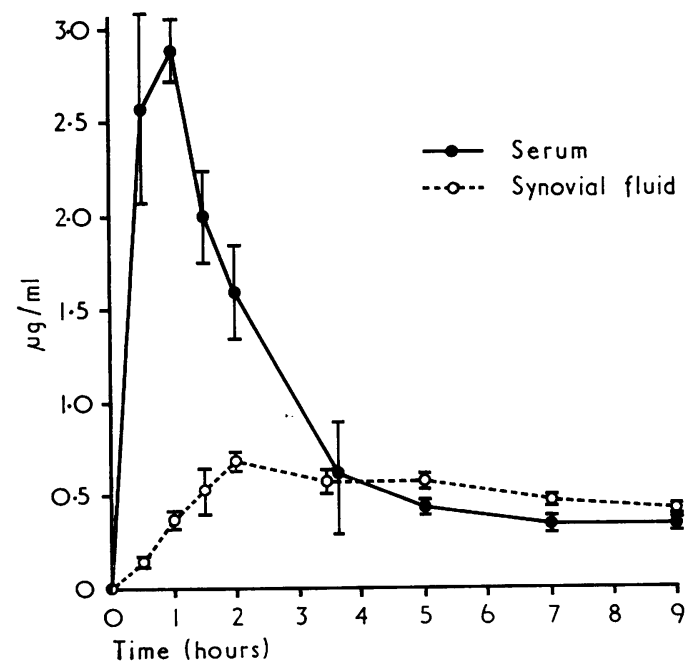

FIG. 1 Serum and synovial fluid concentrations after a single $50 \mathrm{mg}$. oral dose of indomethacin (seven patients, eight trials, mean with SEM)
After reaching peak values, serum levels declined rapidly and when measured $3 \frac{1}{2} \mathrm{hrs}$ after the dose, were not significantly different from synovial fluid levels (means of 0.61 and $0.59 \mu \mathrm{g} . / \mathrm{ml}$. respectively). For the remainder of the study synovial fluid levels were slightly, but significantly, higher than serum levels at the 5- and 7-hr specimens ( $P=0.05$ and 0.02 respectively). At 9 hours the difference was not significant.

Between $1 \mathrm{hr}$ (peak values) and $2 \frac{1}{2} \mathrm{hrs}$ the half-time of drug disappearance from the serum ranged from 40 to 90 min. (mean 60). During the same time period the half-time of drug appearance into the synovial fluid ranged from 60 to $120 \mathrm{~min}$. (mean 75). After equilibration of drug levels in serum and synovial fluid $5 \mathrm{hrs}$ after the dose, the half-time of disappearance from both compartments ranged from 3 to 16 hrs (mean 9) (Fig. 2).

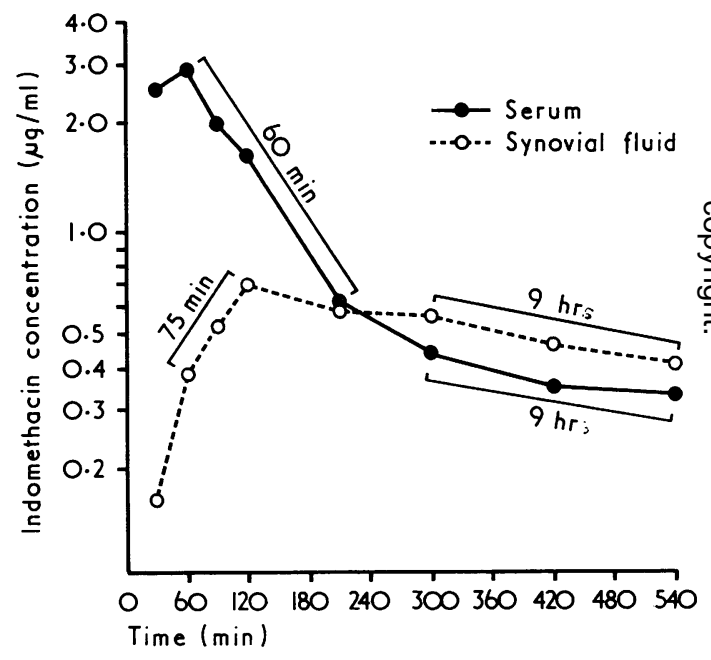

FIG. 2 Semilogarithmic plot of serum and synovial fuid indomethacin concentrations with superimposed half-lives (mean 8 trials, 7 patients) after a single $50 \mathrm{mg}$. oral dose. The half-lives were computed from the drug concentrations during the periods indicated by the solid brackets $(\neg)$.

\section{Discussion}

This study has demonstrated that after oral administration of indomethacin (to patients with RA) the drug readily enters the synovial fluid. However, the appearance of drug in the synovial space was somewhat delayed; thus the peak synovial fluid concentration occurred one hour later than the serum peak level and was only 25 per cent. as great. During the initial phase of equilibration the half-time for disappearance of indomethacin from serum was only $1 \mathrm{hr}$ which is identical to the value of Caruso (1971) and less than that computed by Duggan and others (1972) ( $90 \mathrm{~min}$.). The half-time for appearance in synovial fluid was 
only slightly longer during the same time period. After equilibrium had been established, the half-time for disappearance was much longer $(9 \mathrm{hrs})$ and was the same for both compartments, although drug concentration in synovial fluid was slightly higher than that in serum.

These pharmacokinetic findings are qualitatively similar to the serum and synovial fluid pharmacokinetics reported for acetylsalicylic acid (ASA) (Sholkoff, Eyring, Rowland, and Riegelman, 1967) although the half-time for disappearance of ASA is more rapid. They differ from those of salicylate (Rosenthal, Bayles, and Fremont-Smith, 1964) and gold (Gerber, Paulus, Bluestone, and Lederer, 1972) for which the drug concentration in synovial fluid is substantially lower than that in the serum after equilibration. The lower synovial salicylate concentrations have been explained by the lower albumin concentrations available for drug binding in synovial fluid (Soren, 1970). However, the reason for higher synovial fluid concentrations of indomethacin and ASA (which are also highly bound to albumin) is unclear. Conceivably, active transport is required for these drugs to cross the synovial membrane, thus delaying equilibration. If they then were only slowly metabolized in the joint space while they were more rapidly metabolized or excreted from the serum, higher synovial fluid concentrations might result. Duggan and others (1972) suggest the presence of a hypothetical organ or body compartment in which indomethacin gradually reaches peak levels with a subsequent gradual decline in drug levels; these kinetics in such a compartment could explain the previously observed onset and duration of the therapeutic response to indomethacin. The data presented in our study would suggest that the kinetics observed for the synovial space would be compatible with the therapeutic response observed in clinical practice.

This study demonstrates that $5 \mathrm{hrs}$ after a single 50-mg. oral dose of indomethacin serum and synovial fluid drug concentrations are closely approximated and remain approximated thereafter. One can therefore infer synovial fluid concentrations from those of serum specimens if obtained at least $5 \mathrm{hrs}$ after drug ingestion, obviating the necessity for arthrocentesis. These observations now pave the way for meaningful efficacy studies with this drug.

\section{Summary}

The simultaneous pharmacokinetics of indomethacin in the serum and synovial fluid of seven patients with rheumatoid arthritis were studied after a single 50-mg. oral dose. A spectrophotofluorometric assay for indomethacin was used.

Indomethacin readily appears in the serum and synovial fluid. The kinetics of the synovial fluid concentrations may reflect the temporal characteristics of the therapeutic response to indomethacin. The data presented clear the way for meaningful efficacy studies with the drug in rheumatoid arthritis.

Folke Sjoqvist from the Karolinska Institute, Hudding University Hospital, Stockholm, Sweden provided useful suggestions and E. Sarkissian and L. Tanz provided technical assistance.

\section{References}

CARuso, I. (1971) Arzneimittel-Forsch., 21, 1824 (Verteilung von indometacin in blut und synovialflussigkeit chronischer Polyarthritiker)

Champion, G. D., Paulus, H. E., Mongan, E., Okun, R., Pearson, C. M., and Sarkissian, E. (1972) Clin. Pharmacol. Ther., 13, 239 (The effect of aspirin on serum indomethacin)

Duggan, D. E., Hogans, A. F., Kwan, K. D., and McMahon, F. G. (1972) J. Pharm. exp. Ther., 181, 563 (The metabolism of indomethacin in man)

Gerber, R. C., Paulus, H. E., Bluestone, R., ANd Lederer, M. (1972) Arthr. and Rheum., 15, 625 (Kinetics of aurothiomalate in serum and synovial fluid)

Hucker, H. B., Zacchei, A. G., Cox, S. V., Brodie, D. A., ANd Cantwell, N. H. R. (1966) J. Pharm. exp. Ther., 153, 237 (Studies on the absorption distribution and excretion of indomethacin in various species)

Hvidberg, E., LAUSEN, H. H., AND JanSEN, J. A. (1972) Europ. J. clin. Pharmacol., 4, 119 (Indomethacin: Plasma concentrations and protein binding in man)

Koch-Weser, J. (1972) New Engl. J. Med., 287, 227 (Serum drug concentrations as therapeutic guides)

Rosenoer, V. M., AND GILl, G. M. (1972) Med. Clin. N. Amer., 56, 585 (Drug interactions in clinical medicine)

Ropes, M. W., Bennett, G. A., Cobb, S., Jacox, R., AND Jessar, R. A. (1959) Ann. rheum. Dis., 18, 49 (Diagnostic criteria for rheumatoid arthritis. 1958 revision)

Rosenthal, R. K., BAYLes, T. B., AND Fremont-Smith, K. (1964) Arthr. and Rheum., 7, 103 (Simultaneous salicylate concentrations in synovial fluid and plasma in rheumatoid arthritis)

Sholkoff, S. D., Eyring, E. J., Rowland, M., AND RigGelmaN, S. (1967) Ibid., 10, 348 (Plasma and synovial fluid concentrations of acetylsalicyclic acid in patients with rheumatoid arthritis)

Soren, A. (1970) Clin. Orthop., 68, 322 (Salicylates in blood and joint fluid after ingestion of buffered aspirin)

ZvAIFLER, N. J. (1970) Arthr. and Rheum., 13, 895 (Further speculation on the pathogenesis of joint inflammation in rheumatoid arthritis) 